\title{
Metodologias ativas para o ensino na graduação na área de Computação
}

\author{
Amanda Körber Hartwig, Marlei Maria Silveira, Leonardo Fronza, \\ Heitor Ugarte, Mauro M. Mattos, Luciana P. de Araújo Kohler \\ ${ }^{1}$ Laboratório de Desenvolvimento e Transferência de Tecnologia (LDTT) \\ Departamento de Sistemas e Computação \\ Universidade Regional de Blumenal (FURB) - Blumenau, SC - Brazil
}

\begin{abstract}
Active learning methodologies is a teach strategy that put the user in the center of learning, this is, the student is the protagonist and the professor/teacher is a mediator of teaching-learning proccess. The existing active learning methodologies tend to encourage more the student and involves him better in the classes. In this way, this paper presents some active learning methodologies used in classroom to teach computing for undergraduate students. Among the methodologies are the Problem-Based Learning and the station rotation. As one of the factor of active methodologies is the teach customization, the paper present the use of EdModo tool with this intention.
\end{abstract}

Resumo. Metodologia ativa é uma estratégia de ensino que coloca o usuário como centro do aprendizado, sendo ele o protagonista e o professor um mediador do processo de ensino-aprendizagem. As metodologias ativas existentes tendem a incentivar mais o aluno e a envolve-lo melhor nas disciplinas. Dessa forma, este artigo apresenta algumas metodologias ativas utilizadas em sala de aula no ensino da computação para alunos da graduação. Dentre as metodologias ativas está a Aprendizagem Baseada em Problemas e as rotações por estação. Ainda, como um dos fatores das metodologias ativas é a personalização do ensino, o artigo apresenta o uso da ferramenta EdModo com esta finalidade.

\section{Introdução}

A cultura digital crescente na vida cotidiana das pessoas vem influenciando a forma com que os indivíduos aprendem, consultam informações, participam de grupos e trocam experiências entre si [Bacich and Moran 2018]. Com ela, a forma com a qual o aluno interage em sala de aula também está mudando, visto que ele tem as informações nos meios digitais, sendo assim tem-se a questão: qual é o papel da universidade ou do professor para o aluno se este aluno consegue as informações através de outros meios? A partir dessa questão, autores como [Bacich and Moran 2018] e [Bray and McClaskey 2016] trazem experiências, relatos e estudos na área de metodologias ativas aplicadas ao ensino de modo que o papel entre professor e aluno seja modificado. A partir das metodologias ativas, o aluno recebe o foco principal do ensino-aprendizagem, sendo o protagonista do aprendizado e o professor e o responsável por instigá-lo a aprender e a evoluir seu conhecimento através da informação disponível. Ocorre que, em meio a tanta informação, o professor também precisa se preparar para receber esse aluno e realizar aulas voltadas a eles de forma personalizada, na qual cada um desenvolverá mais as habilidades que lhes 
VIII Congresso Brasileiro de Informática na Educação (CBIE 2019)

Anais do XXV Workshop de Informática na Escola (WIE 2019)

competem. Para isso, é importante o estudo das tecnologias de informação que auxiliam na prática do ensino híbrido, pois através delas as metodologias ativas são mescladas entre tecnologia e ensino presencial.

$\mathrm{Na}$ Universidade Regional de Blumenau (FURB) iniciou-se a prática dessas metodologias, principalmente nos cursos na área da Computação. Diante desse contexto, este artigo apresenta a experimentação realizada com a turma da disciplina de Testes de Software que ocorreu de forma concentrada, na qual foram utilizadas essas metodologias durante toda a disciplina para estimular o ensino-aprendizagem e permitir a personalização do mesmo. Sendo assim, o objetivo do experimento e testar as metodologias ativas no ensino da graduação e verificar se os alunos se sentem mais engajados e motivados a realizar as atividades e a desenvolver seus saberes.

\section{Prática em sala de aula}

Afim de testar as metodologias ativas em sala de aula mudando a forma de ensinar, com o objetivo de envolver os alunos durante todo o processo de ensino-aprendizagem, foram aplicadas as metodologias ativas de Aprendizagem Baseada em Problemas (do inglês, Problem Based Learning - PBL) e rotação por estações.

Para a personalização do ensino e a disposição do material, sendo tanto o material pedagógico, quanto as atividades, foi utilizada a plataforma de ensino EdModo. A prática durou por um período de 9 aulas de 210 minutos cada ( 3 horas e 30 minutos) acontecendo de forma concentrada, ou seja, todos os dias da semana durante uma semana e meia.

O Edmodo é uma ferramenta que serve para conectar alunos aos seus professores de forma que eles possam colaborar, realizar tarefas em equipe, trocar mensagens, entre outras funcionalidades. Semelhante a uma rede social, a ferramenta permite que o professor crie suas turmas, convide seus alunos, compartilhe materiais, disponibilize atividades que podem ser colaborativas ou individuais e ainda permite a troca de mensagens através de postagens em timelines ou chat.

Para o uso do EdModo na sala de aula, criou-se uma turma e compartilhou-se o link desta turma com os alunos de modo que pudessem participar da mesma. Após a conexão dos alunos a turma, foi criada uma pasta compartilhada com eles contendo os materiais de apoio para o ensino-aprendizagem na área de testes e avaliação de software. Os materiais foram atribuídos a pasta de uma vez só, de modo que cada aluno ao finalizar uma leitura já pudesse ir para a próxima, tendo assim sua própria evolução do saber.

Com relação as metodologias ativas, para a Aprendizagem Baseada em Problemas (PBL) foram disponibilizados vários problemas na timeline da turma de modo que cada equipe escolhesse o problema que mais a interessava. As atividades aconteceram em grupos entre 3 e 4 alunos, sendo um total de quatro grupos. A vantagem dos grupos é que um aluno aprende com o outro, trocando informações para o aprendizado dos novos saberes. No entanto, é uma missão difícil para o professor identificar quais alunos realmente estão engajados nas tarefas e quais estão colaborando com a equipe, visto que simplesmente dividir tarefas não representa um trabalho em grupo.

A partir da escolha do problema, o grupo tinha que desenvolver uma solução de acordo com o contexto da disciplina e em seguida apresenta-la para a turma. Essa atividade ocorreu por aproximadamente 3 aulas, sendo que na ultima houve a apresentação 
VIII Congresso Brasileiro de Informática na Educação (CBIE 2019)

Anais do XXV Workshop de Informática na Escola (WIE 2019)

para toda a turma. Para solucionar o problema, os alunos tinham que pesquisar no material fornecido pela professora via EdModo, além de pesquisar na web soluções extras e alternativas, conforme o contexto de cada um. Como cada time trabalhou em uma contextualização diferenciada, quando houve a socialização todos aprenderam um pouco novamente, pois puderam trocar experiências distintas e discutir a respeito de soluções encontradas por outros membros.

Além da PBL, também foram realizadas rotações por estações para a prática de TDD e BDD. Essa pratica também foi realizada em equipes entre 3 e 4 alunos e houveram 4 estações, sendo elas: construção de um cenário, criação do teste unitário, implementação e validação da implementação. A diferença do método aplicado para a rotação por estações original é que todos começavam na estação 1 e assim continuavam até chegar na última estação. No caso, o que rotacionava era a atividade que eles estavam realizando, sendo que o cenário construído pela equipe 1 era testado pela equipe 2 , o cenário construído pela equipe 2 era testado pela equipe 3 e assim por diante. Conforme as estações, as equipes tinham de 10 à 30 minutos para a realização da atividade. Na Figura 1 pode-se observar os grupos trabalhando nas atividades propostas.

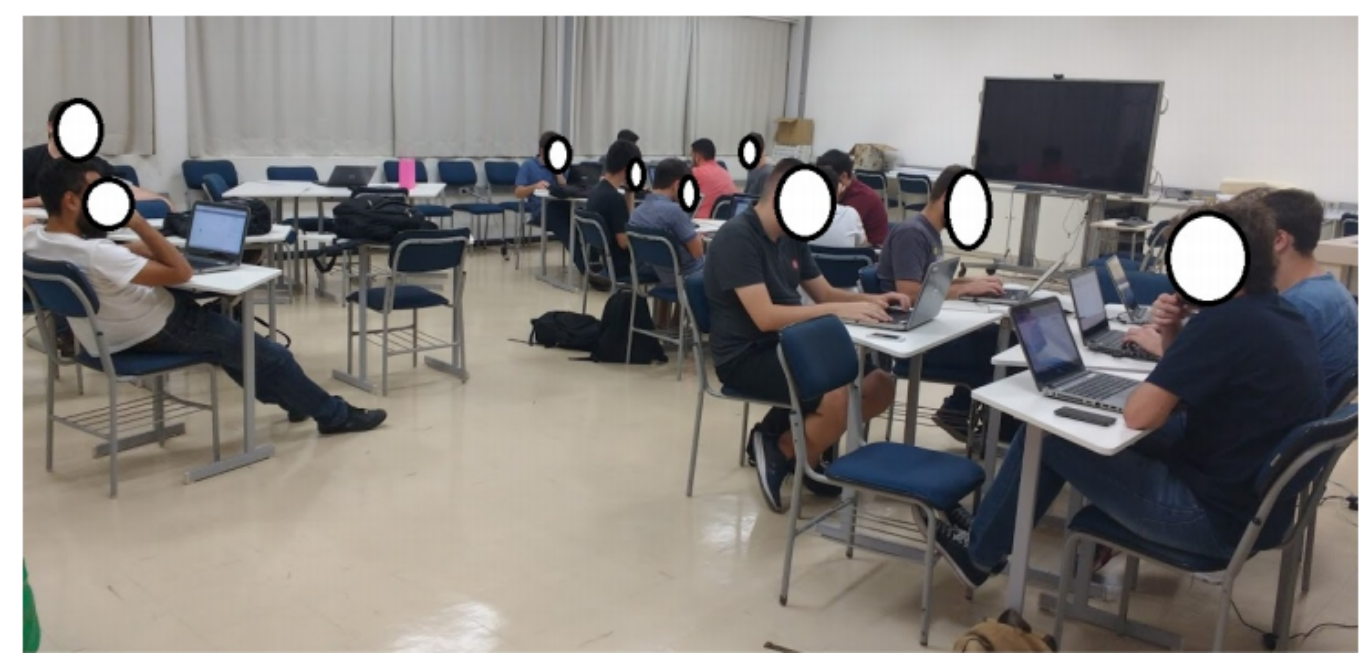

Figura 1. Aplicação em sala de aula

\section{Resultados}

Ao final da disciplina foi realizado um questionário de satisfação com os acadêmicos para que pudesse ser avaliado o uso dessas metodologias ativas para o aprendizado deles. Para a realização da avaliação utilizou-se um questionário de satisfação de uso adaptado para o contexto da disciplina, sendo apresentado na Figura 2. As 7 primeiras questões tinham como opções de resposta uma escala de likert entre 1 e 5, sendo 1 discordo totalmente e 5 concordo totalmente. A questão 8 teve um conjunto de elementos a serem escolhidos e as demais eram questões dissertativas para que o acadêmico pudesse expressar seus sentimentos e opiniões. Não foi solicitado o nome e questões de perfil para privar sua identidade e deixa-lo a vontade ao responder o questionário.

Dos quinze alunos matriculados na disciplina, doze responderam o questionário. Com base nas cinco primeiras questões, pode-se afirmar que a maioria dos alunos estão 
VIII Congresso Brasileiro de Informática na Educação (CBIE 2019)

Anais do XXV Workshop de Informática na Escola (WIE 2019)

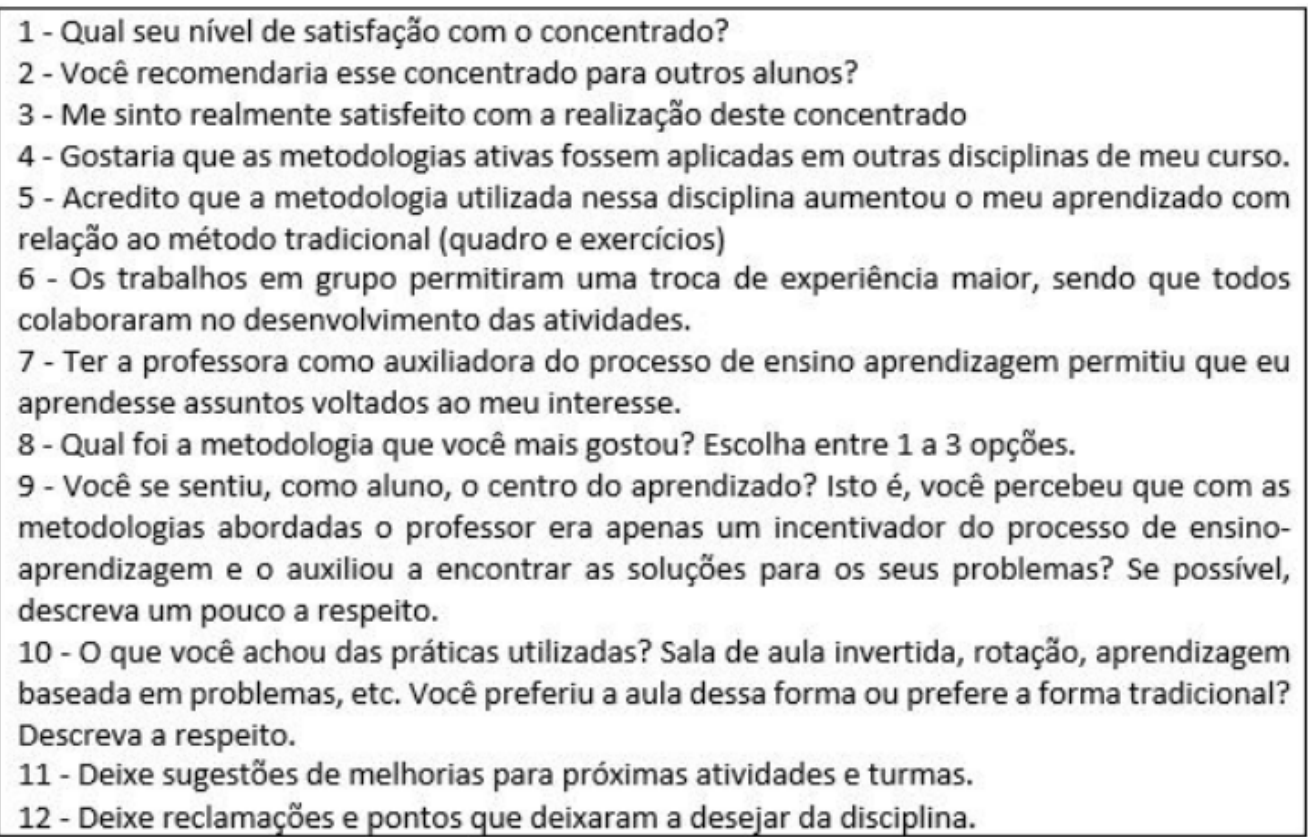

Figura 2. Perguntas do questionário de satisfação

satisfeitos com as metodologias ativas aplicadas na disciplina, visto que o percentual para a escala 5 é maior que $50 \%$ em todas elas.

Ainda, com relação a metodologia que os acadêmicos mais gostaram foi a aprendizagem baseada em problemas e a rotação por estações, abordadas neste trabalho. Além dessas, foram aplicadas também experimentações de sala de aula invertida que teve 2 votos e construção de artigo em conjunto que também teve 2 votos.

Já com relação as questões dissertativas, de forma geral os alunos mencionaram que se sentiram concentrados no aprendizado, sendo motivados a estudar e aprender o conteúdo proporcionado. Houve também descrições relatando que a aula é mais dinâmica, saindo da monotonia da sala de aula tradicional, permitindo que o aluno tivesse mais vontade de aprender. Outro ponto levantado foi a personalização, pois desta forma cada um pode trabalhar com ferramentas desejadas e aprender os conteúdos relacionados ao seu uso cotidiano.

\section{Considerações Finais}

Tendo em vista que o objetivo do artigo é testar as metodologias ativas no ensino da graduação e verificar se os alunos se sentem mais engajados e motivados a realizar as atividades e a desenvolver seus saberes, pode-se afirmar que o mesmo foi cumprido. A primeira parte do objetivo foi alcançada, pois foram testadas as metodologias ativas de rotação por estações, aprendizagem baseada em problemas e outras técnicas como sala de aula invertida, grupos de trabalhos e colaboração em texto online. Já a segunda parte, pode-se afirmar que os alunos se sentem mais engajados em seus afazeres, pois conforme a avaliação realizada ao final da disciplina, os acadêmicos apontaram vários pontos positivos e avaliaram como escala de likert 5.

Dessa forma, como próximos passos, pretende-se estruturar as metodologias uti- 
VIII Congresso Brasileiro de Informática na Educação (CBIE 2019)

Anais do XXV Workshop de Informática na Escola (WIE 2019)

lizadas de modo que possa ser replicada facilmente em outras turmas e semestres. Ainda, pretende-se aumentar a experimentação testando a aprendizagem baseada em projetos e outras formas de metodologias ativas.

\section{Referências}

Bacich, L. and Moran, J. (2018). Metodologias Ativas para uma Educação Inovadora: Uma Abordagem Teórico-Prática. Penso.

Bray, B. A. and McClaskey, K. A. (2016). How to Personalize Learning: A Practical Guide for Getting Started and Going Deeper (Corwin Teaching Essentials). Corwin. 